\title{
Berberine, a natural plant alkaloid, synergistically sensitizes human liver cancer cells to sorafenib
}

\author{
YUEZHAO HUANG $^{1 *}$, KUNYUAN WANG $^{1 *}$, CHENGXIN GU $^{1}$, GANXIANG YU $^{1}$, DAN ZHAO ${ }^{1}$, \\ WEIJIAN MAI ${ }^{1}$, YUN ZHONG ${ }^{2}$, SHIMING LIU ${ }^{2}$, YUQIANG NIE ${ }^{3}$ and HUI YANG ${ }^{1}$ \\ ${ }^{1}$ Department of Gastroenterology; ${ }^{2}$ Guangzhou Institute of Cardiovascular Disease, \\ The Second Affiliated Hospital of Guangzhou Medical University, Guangzhou, Guangdong 510260; \\ ${ }^{3}$ Department of Gastroenterology, Guangzhou First People's Hospital of Guangzhou Medical University, \\ Guangzhou, Guangdong 510180, P.R. China
}

Received January 11, 2018; Accepted July 2, 2018

DOI: $10.3892 /$ or.2018.6552

\begin{abstract}
Sorafenib resistance is one of the major factors affecting the prognosis of patients with hepatocellular carcinoma (HCC). Increasing evidence has indicated that certain traditional medicines can enhance the sensitivity of cancer cells to sorafenib. Berberine, an isoquinoline alkaloid, has been demonstrated to possess antitumor properties against various malignancies. However, the synergistic effect of the combination of berberine and sorafenib in HCC remains unknown. The aim of the present study was to determine the effects of berberine and sorafenib combination on the growth of liver cancer cells. Initially, it was observed that the combination of sorafenib and berberine exerted a synergistic inhibitory effect on the proliferation of SMMC-7721 and HepG2 cells in a dose- and time-dependent manner by an MTS assay. Edu staining and colony formation assays also revealed that the combination of $100 \mu \mathrm{M}$ berberine and $4 \mu \mathrm{M}$ sorafenib exhibited a significant anti-proliferation effect on SMMC-7721 and HepG 2 cells. Furthermore, western blotting assay indicated that the expressions levels of cleaved poly(ADP-ribose) polymerase and cleaved caspase- 3 increased, while those of the anti-apoptotic protein B-cell lymphoma 2 and vascular endothelial growth factor decreased. To the best of our knowledge, this is the first study to demonstrate that berberine sensitized liver cancer cells to sorafenib treatment. These results suggest that berberine combined with sorafenib is able to inhibit the proliferation of liver cancer cells and induce
\end{abstract}

Correspondence to: Dr Hui Yang, Department of Gastroenterology, The Second Affiliated Hospital of Guangzhou Medical University, 250 Changgang East Road, Guangzhou, Guangdong 510260, P.R. China

E-mail: yanghui@gzhmu.edu.cn

*Contributed equally

Key words: berberine, sorafenib, cytotoxicity, hepatocellular carcinoma apoptosis, which provides evidence for further clinical investigation in HCC patients with sorafenib resistance.

\section{Introduction}

Hepatocellular carcinoma (HCC) is the second leading cause of cancer-associated mortality worldwide, and its morbidity and mortality rates are steadily increasing $(1,2)$. Although the therapeutic approaches for HCC have improved during the past few years, the prognosis of HCC patients remains unsatisfactory since diagnosis is often made at an advanced stage and, therefore, these patients cannot be treated with surgery (3).

Sorafenib (Nexavar), a multikinase inhibitor, is the first and only systemic agent approved for the treatment of patients with advanced HCC $(4,5)$. It inhibits multiple cell surface tyrosine kinases and downstream intracellular serine/threonine kinases in the mitogen-activated protein kinase cascade, including vascular endothelial growth factor receptor (VEGFR)-1, VEGFR-2 and VEGFR-3, as well as platelet-derived growth factor receptor- $\beta(4,6,7)$. Furthermore, previous studies have demonstrated that certain microRNA (miR) molecules, such as miR-1274a and miR-125a-5p, are involved in HCC target-chemotherapy with sorafenib $(8,9)$. Although it has been reported that sorafenib improves the overall survival of patients with advanced HCC, the majority of patients ultimately develop resistance to sorafenib $(4,5,10)$. Recently, sorafenib has been administered in combination with other agents. Previous research has revealed that the combination of sorafenib and triptolide is superior to single drug treatment in increasing cell death and apoptosis in vitro, and inhibiting tumor growth in vivo (11). The combination of sorafenib and aspirin resulted in a synergistic antitumor effect against liver tumors both in vitro and in vivo (12). However, clinical investigations associated with these studies have not been conducted to date. Therefore, it is necessary to develop novel combination therapies to potentiate the anticancer effect of sorafenib and facilitate its clinical application.

Berberine is an isoquinoline alkaloid isolated from species belonging to various plant families, including the Berberidaceae, Ranunculaceae and Papaveraceae families $(13,14)$. It is traditionally used as an antibiotic to treat 
dysentery, gastrointestinal diseases and diarrhea in China, and is a relatively cheap compound $(14,15)$. Previous studies have reported that berberine exerts an anticancer activity in multiple types of cancer and inhibits the proliferation of cancer cells by inducing apoptosis (16-19). The possible molecular mechanism of the effect of berberine involves its interaction with numerous molecular targets, including transcription factors, cytokines, enzymes, receptors, oncomiRs and tumor-suppressive miRs (20). Furthermore, it has been reported that berberine suppresses tumor development when used in combination with other chemotherapeutic agents. For instance, the combination of berberine and evodiamine enhanced the apoptosis of SMMC-7721 cells (21), while berberine in combination with cisplatin exhibited high synergistic inhibitory effects on the growth of HeLa cells (22). These findings suggest that berberine is a potential antitumor drug with fewer side effects and a low price. However, the combined efficacy of berberine and sorafenib in the treatment of HCC has not been reported.

In the present study, the aim was to explore the effect of the combination of berberine and sorafenib on the growth of HCC cells. The data of this study indicated for the first time that berberine in combination with sorafenib exerts an inhibitory effect on the proliferation of liver cancer cells and induces cellular apoptosis. Thus, combined treatment with sorafenib and berberine may be a novel therapeutic strategy for HCC patients with sorafenib resistance.

\section{Materials and methods}

Cells and reagents. Two HCC cell lines (SMMC-7721 and HepG2) were obtained from the American Type Culture Collection (ATCC; Manassas, VA, USA). The cells were cultured in Dulbecco's modified Eagle's medium (DMEM; Gibco; Thermo Fisher Scientific, Inc., Waltham, MA, USA; cat. no. 8117220;) supplemented with $10 \%(\mathrm{v} / \mathrm{v})$ fetal bovine serum (FBS) and 1\% (v/v) penicillin/streptomycin (Gibco; Thermo Fisher Scientific, Inc.; cat. no. 10-378-016) and maintained at $37^{\circ} \mathrm{C}$ in a $5 \% \mathrm{CO}_{2}$ incubator. Berberine was purchased from Selleck Chemicals (Houston, TX, USA; cat. no. S2271). Sorafenib was purchased from MedChemExpress (Monmouth Junction, NJ, USA; cat. no. Y-10201). Dimethyl sulfoxide (DMSO) was obtained from Sigma-Aldrich (Merck KGaA, Darmstadt, Germany; cat. no. 67-68-5).

Cell viability assays. The cells were seeded at a density of 3,000 cells/well in a 96-well plate. After $24 \mathrm{~h}$ of incubation, the indicated concentrations of sorafenib $(0,1,2$, 4 and $8 \mu \mathrm{M})$ or berberine $(0,5,25,50$ and $100 \mu \mathrm{M})$ alone, or their combination $(1 \mu \mathrm{M}$ sorafenib $+5 \mu \mathrm{M}$ berberine; $1 \mu \mathrm{M}$ sorafenib $+25 \mu \mathrm{M}$ berberine; $1 \mu \mathrm{M}$ sorafenib $+50 \mu \mathrm{M}$ berberine; $1 \mu \mathrm{M}$ sorafenib $+100 \mu \mathrm{M}$ berberine; $2 \mu \mathrm{M}$ sorafenib $+5 \mu \mathrm{M}$ berberine; $2 \mu \mathrm{M}$ sorafenib $+25 \mu \mathrm{M}$ berberine; $2 \mu \mathrm{M}$ sorafenib $+50 \mu \mathrm{M}$ berberine; $2 \mu \mathrm{M}$ sorafenib $+100 \mu \mathrm{M}$ berberine; $4 \mu \mathrm{M}$ sorafenib $+5 \mu \mathrm{M}$ berberine; $4 \mu \mathrm{M}$ sorafenib $+25 \mu \mathrm{M}$ berberine; $4 \mu \mathrm{M}$ sorafenib $+50 \mu \mathrm{M}$ berberine; $4 \mu \mathrm{M}$ sorafenib $+100 \mu \mathrm{M}$ berberine; $8 \mu \mathrm{M}$ sorafenib $+5 \mu \mathrm{M}$ berberine; $8 \mu \mathrm{M}$ sorafenib $+25 \mu \mathrm{M}$ berberine; $8 \mu \mathrm{M}$ sorafenib $+50 \mu \mathrm{M}$ berberine; $8 \mu \mathrm{M}$ sorafenib $+100 \mu \mathrm{M}$ berberine) were added to each well and incubated for $48 \mathrm{~h}$. Mock treatment with an identical volume of DMSO was used as a control. In addition, treatment with a combination of $4 \mu \mathrm{M}$ sorafenib and $100 \mu \mathrm{M}$ berberine was tested after incubation for three different time-points $(24,48$ and $72 \mathrm{~h})$. Next, the cell viability was measured with the MTS method. Briefly, $20 \mu 1$ MTS dye solution was mixed with $100 \mu$ l DMEM in each well and cultured for $2.5 \mathrm{~h}$ at $37^{\circ} \mathrm{C}$. The optical density (OD) values were read at $490 \mathrm{~nm}$ using a Synergy H1/Epoch microplate reader (BioTek Instruments, Inc., Winooski, VT, USA). Cell viability rate was calculated according to the following formula: Cell viability $(\%)=$ (the mean OD value of drug - treated sample/the mean OD value of control sample) x $100 \%$.

EdU incorporation assay. For evaluation of cell proliferation, the Cell-Light ${ }^{\mathrm{TM}}$ EdU Apollo ${ }^{\circledR} 567$ in vitro Imaging kit (Guangzhou RiboBio Co., Ltd., China) was used, and the EVOS FL High Content Imaging System was used to obtain and analyze images of the cell cultures. Briefly, following the drug treatment, $50 \mu \mathrm{M}$ EdU was added to each well and incubated for $2 \mathrm{~h}$ to facilitate its integration into the $\mathrm{S}$ phase of DNA. The cells in the 96-well plate were then washed twice with phosphate-buffered saline (PBS) and fixed with $4 \%$ paraformaldehyde for $30 \mathrm{~min}$ at $25^{\circ} \mathrm{C}$. Next, the cells were washed once with $2 \mathrm{mg} / \mathrm{ml}$ glycine and treated with $0.5 \%$ Triton X-100 at $25^{\circ} \mathrm{C}$ for $10 \mathrm{~min}$. Following permeabilization, the cells were incubated with $100 \mu \mathrm{l} 1 \mathrm{X}$ Apollo reaction mixture at $25^{\circ} \mathrm{C}$ for $30 \mathrm{~min}$ in the dark, washed with $0.5 \%$ Triton X-100 twice for $10 \mathrm{~min}$, and then washed twice with methanol for $5 \mathrm{~min}$. The cell nucleus was stained with Hoechst 33342 reaction mixture and washed with PBS for $10 \mathrm{~min}$. Finally, the EVOS FL High Content Imaging System was used to obtain and analyze images of the cells.

Colony formation assay. In total, 1,000 cells were cultured per well in a 6-well plate. After 10 days of growth, the cells were treated with $4 \mu \mathrm{M}$ sorafenib and $100 \mu \mathrm{M}$ berberine alone or in combination for $72 \mathrm{~h}$. Mock treatment with an identical volume of DMSO was used as a control. The cells were washed with PBS twice, fixed with methanol for 15 min at room temperature, and stained with crystal violet for $15 \mathrm{~min}$. Colonies with $>50$ cells were counted under an ordinary optical microscope.

Western blotting. The cells were seeded in a $60-\mathrm{mm}$ plate at the density of $1.0 \times 10^{5}$ cells/well and cultured in DMEM with $10 \%$ FBS and $1 \%(\mathrm{v} / \mathrm{v})$ penicillin/streptomycin. Following treatment with $4 \mu \mathrm{M}$ sorafenib and $100 \mu \mathrm{M}$ berberine alone or in combination for $72 \mathrm{~h}$, the cells were washed with cold PBS and harvested. The harvested cells were lysed with ice-cold radioimmunoprecipitation assay buffer containing $2 \%$ protease/phosphatase inhibitor, $1 \%$ phenylmethylsulfonyl fluoride and $1 \%$ protease inhibitor cocktail (Thermo Fisher Scientific, Inc.) for $20 \mathrm{~min}$. Subsequent to lysis by ultrasonication (Sonics Vibra-Cell; Sonics \& Materials, Inc., Newtown, CT, USA), the lysates were centrifuged at $13,400 \mathrm{xg}$ for $15 \mathrm{~min}$ at $4^{\circ} \mathrm{C}$. Total protein concentrations of the lysates were assessed using the BCA protein quantification kit (Thermo Fisher Scientific, Inc.). Protein extracts $(50 \mu \mathrm{g})$ were separated by $8 \%$ sodium dodecyl 
sulfate-polyacrylamide gel electrophoresis (SDS-PAGE), and then transferred onto methanol-activated polyvinylidene fluoride (PVDF) membranes at $90 \mathrm{~V}$ for $1.5 \mathrm{~h}$. After blocking the PVDF membranes with $5 \%$ non-fat milk for $1 \mathrm{~h}$ at $25^{\circ} \mathrm{C}$, the membranes were probed with primary antibodies at $4^{\circ} \mathrm{C}$ for $12 \mathrm{~h}$, including anti-poly(ADP-ribose) polymerase (PARP; 1:1,000; cat. no. 9532; Cell Signaling Technology, Inc., Inc.), cleaved-caspase-3 (1:1,000; cat. no. 9664; Cell Signaling Technology, Inc.), anti-B-cell lymphoma 2 (Bcl-2; 1:1,000; cat. no. 2827; Santa Cruz Biotechnology, Inc., Dallas, TX, USA), anti-VEGF antibodies (1:500; cat. no. 46154; Abcam, Cambridge UK) and anti-GAPDH (1:1,000; cat. no. 2118; Cell Signaling Technology,Inc.). Subsequently, the membranes were incubated with horseradish peroxidase-conjugated anti-rabbit IgG (1:5,000; cat. no. 7074; Cell Signaling Technology, Inc.) secondary antibody for $1 \mathrm{~h}$ at $25^{\circ} \mathrm{C}$. Finally, the protein bands were detected using enhanced chemiluminescence (SuperSignal West Pico Chemiluminescent Substrate; Pierce; Thermo Fisher Scientific, Inc.). All the protein bands were densitometrically scanned and analyzed with Image J software (National Institues of Health, Bethesda, MD, USA). The results of western blotting are representative of at least three independent experiments.

Statistical analysis. All data are expressed as the mean \pm standard deviation of three independent sets of experiments. Student's t-test was used to analyze all experimental data in GraphPad Prism software, version 6 (GraphPad Software, Inc., La Jolla, CA, USA). P $<0.05$ was considered to be an indicator of a statistically significant difference.

\section{Results}

Sorafenib and berberine inhibits the proliferation of HCC cells in a dose-dependent manner. To explore the growth inhibitory effect of sorafenib and berberine, an MTS assay was utilized to assess the viability of HCC cells treated with sorafenib or berberine. The results demonstrated that sorafenib inhibited the growth of SMMC-7721 and HepG2 cells in a dose-dependent manner (Fig. 1A), and that the viability of cells treated with 4 and $8 \mu \mathrm{M}$ sorafenib was reduced to almost 80 and $50 \%$, respectively. It was also observed that treatment with 5 and $25 \mu \mathrm{M}$ berberine enhanced the viability of SMMC-7721 and HepG2 cells by 10-20\% (Fig. 1B). However, cytotoxicity was gradually observed with increasing doses of berberine. Cell viability was inhibited following treatment with 50 and $100 \mu \mathrm{M}$ berberine, while the viability of cells was reduced to $\sim 50 \%$ when treated with $100 \mu \mathrm{M}$ berberine (Fig. 1B). Thus, these findings indicated that sorafenib inhibited the growth of HCC cells in a dose-dependent manner, whereas berberine had a dose-dependent inhibitory effect at sufficiently high concentrations.

Berberine synergistically sensitize HCC cells to sorafenib. To investigate the synergistic effect of sorafenib and berberine, SMMC-7721 and HepG2 cells were exposed to different concentrations of sorafenib $(0,1,2,4$ and $8 \mu \mathrm{M})$ and berberine $(0,5,25,50$ and $100 \mu \mathrm{M})$ alone or in combination. The results of cell viability assay revealed that, with the exception of the 2 or $8 \mu \mathrm{M}$ sorafenib and $5 \mu \mathrm{M}$ berberine combined groups in SMMC-7721 cells, the combination of sorafenib $(1,2,4$ and $8 \mu \mathrm{M})$ and berberine $(5 \mu \mathrm{M})$ promoted cell growth when compared with vehicle or sorafenib treatment alone (Fig. 2A and B). With the increase of berberine concentration, the anti-proliferative effect of the combined treatment was markedly higher in comparison with that of sorafenib treatment alone. The combination of $8 \mu \mathrm{M}$ sorafenib and $100 \mu \mathrm{M}$ berberine had the most marked inhibitory effect (Fig. 2A and B). These results demonstrated that berberine synergistically sensitized HCC cells to sorafenib.

Considering that the combination of $4 \mu \mathrm{M}$ sorafenib and $100 \mu \mathrm{M}$ berberine not only inhibited HCC cell proliferation, but also increases the sensitivity of HCC cells to sorafenib, the combination of $4 \mu \mathrm{M}$ sorafenib and $100 \mu \mathrm{M}$ berberine was selected for subsequent experiments. To further confirm the synergistic effect of sorafenib and berberine, SMMC-7721 and HepG2 cells were treated with $4 \mu \mathrm{M}$ sorafenib and $100 \mu \mathrm{M}$ berberine alone or in combination for 24,48 and $72 \mathrm{~h}$, respectively. The results revealed that the anti-proliferative effect of the combination treatment was significantly greater compared with that of single agent treatment, and that this effect was time-dependent (Fig. 3A and B). The viability of SMMC-7721 and HepG2 cells decreased evidently in the group treated with a combination of $4 \mu \mathrm{M}$ sorafenib and $100 \mu \mathrm{M}$ berberine for $72 \mathrm{~h}$. In addition, crystal violet staining was applied for screening cell viability. Consistent with the findings of the MTS assay, cell proliferation was markedly suppressed in the combined treatment group (Fig. 3C). Similar results were observed for HepG2 cells in the MTS and crystal violet assays (Fig. 3B and 3D). Collectively, berberine plus sorafenib may be a potential therapeutic combination for the inhibition of HCC cell growth.

Combination of berberine and sorafenib suppresses the proliferation and colony formation of HCC cells. Edu and colony formation assays were conducted to assess the short-term and long-term effects of combined treatment with berberine and sorafenib on HCC cell proliferation. As shown in Fig. 4A, the combination of $100 \mu \mathrm{M}$ berberine and $4 \mu \mathrm{M}$ sorafenib significantly decreased the proliferation of SMMC-7721 cells when compared with that of the control and single agent groups. Furthermore, it was observed that HepG2 cells treated with the combination of $100 \mu \mathrm{M}$ berberine and $4 \mu \mathrm{M}$ sorafenib exhibited a lower proliferative ability in comparison with the other groups (Fig. 4B).

Next, the synergistic potential of berberine and sorafenib was further evaluated based on the colony formation efficiency. The results revealed that the largest number of SMMC-7721 cell colonies was formed in the control group, while the lowest number of SMMC-7721 cell colonies was observed in the group treated with the combination of $100 \mu \mathrm{M}$ berberine and $4 \mu \mathrm{M}$ sorafenib (Fig. 5A). Significant differences were observed in the number of colonies between the four groups (Fig. 5B; $\mathrm{P}<0.05$ ). Meanwhile, similar results were observed in HepG2 cells using the colony formation assay (Fig. 5C and D; $\mathrm{P}<0.05$ ). Taken together, the aforementioned results revealed that the combination of berberine and sorafenib inhibited the proliferation and colony formation of HCC cells. 

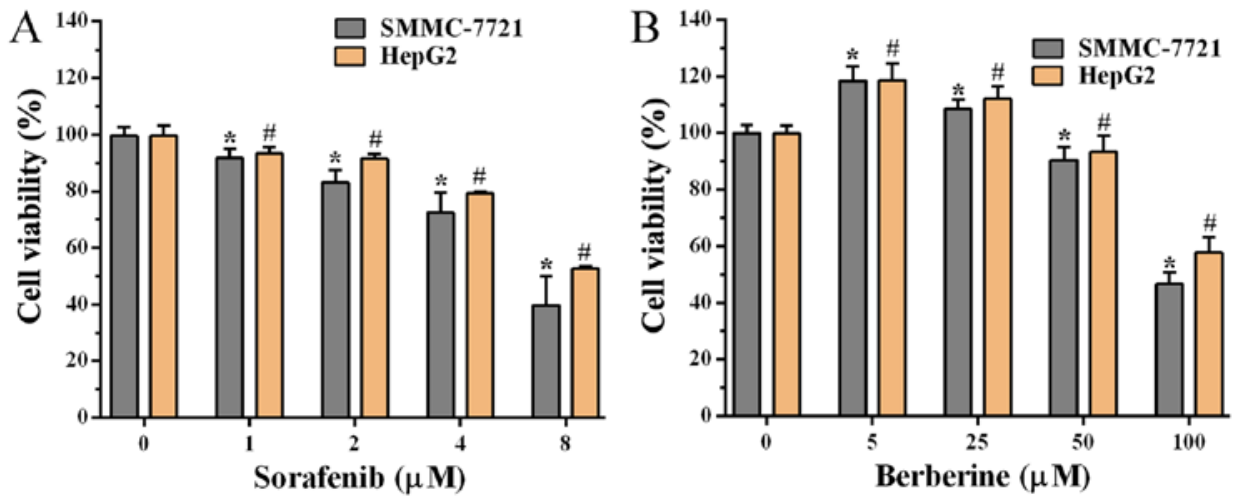

Figure 1. Sorafenib and berberine as single agents inhibited the proliferation of hepatocellular carcinoma cells. SMMC-7721 and HepG2 cells were treated with different concentrations of (A) sorafenib $(0,1,2,4$ and $8 \mu \mathrm{M})$ and (B) berberine $(0,5,25,50$ and $100 \mu \mathrm{M})$ alone for $48 \mathrm{~h}$, and the cell viability was detected by an MTS assay. Cells treated with dimethyl sulfoxide were used as the control group. The experiments were conducted in triplicate, and data are presented as the mean \pm standard deviation. ${ }^{*} \mathrm{P}<0.05$ vs. control in SMMC-7721 cells; ${ }^{*} \mathrm{P}<0.05$ vs. control in HepG2 cells.
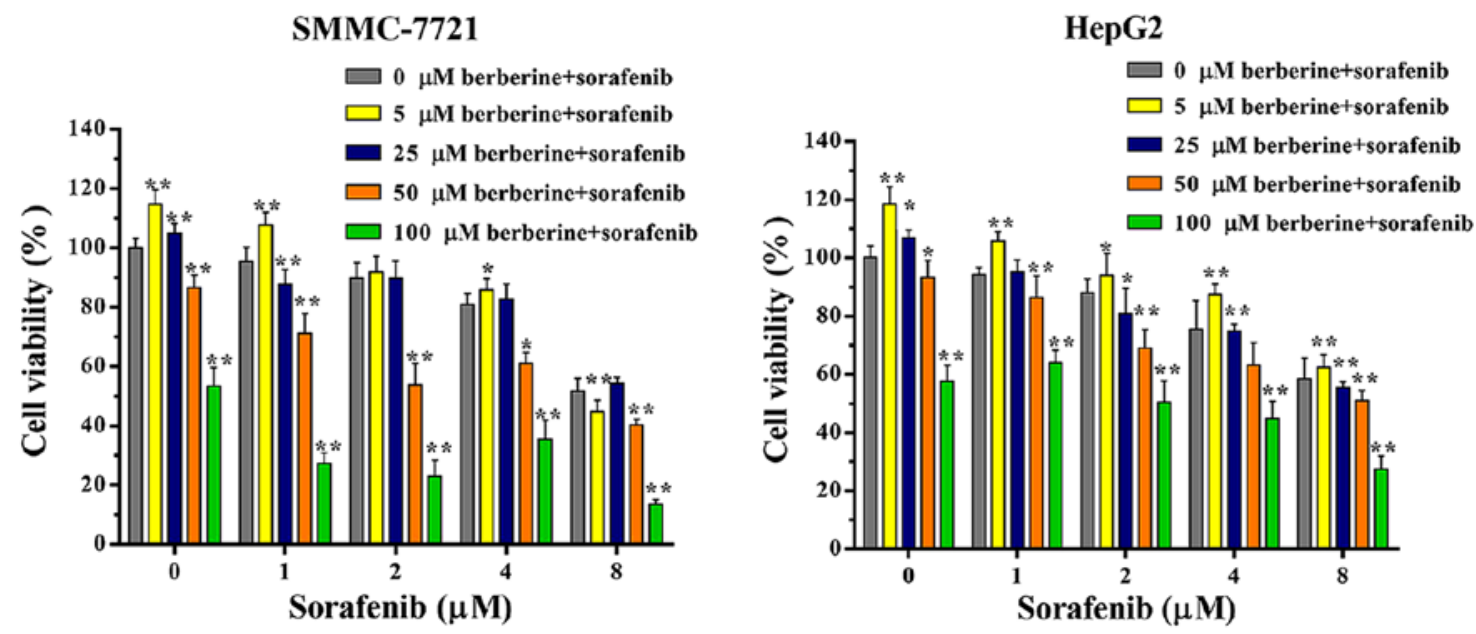

Figure 2. Combination of berberine and sorafenib suppressed hepatocellular carcinoma cell proliferation. (A) SMMC-7721 and (B) HepG2 cells were treated with different concentrations of sorafenib $(0,1,2,4$ and $8 \mu \mathrm{M})$ and berberine $(0,5,25,50$ and $100 \mu \mathrm{M})$ in combination for $48 \mathrm{~h}$, and the cell viability was evaluated by an MTS assay. Data are shown as the mean \pm standard deviation. ${ }^{*} \mathrm{P}<0.05$ and ${ }^{* *} \mathrm{P}<0.01$, vs. vehicle or sorafenib-treated group (t-test; $\mathrm{n}=3$ ).

A

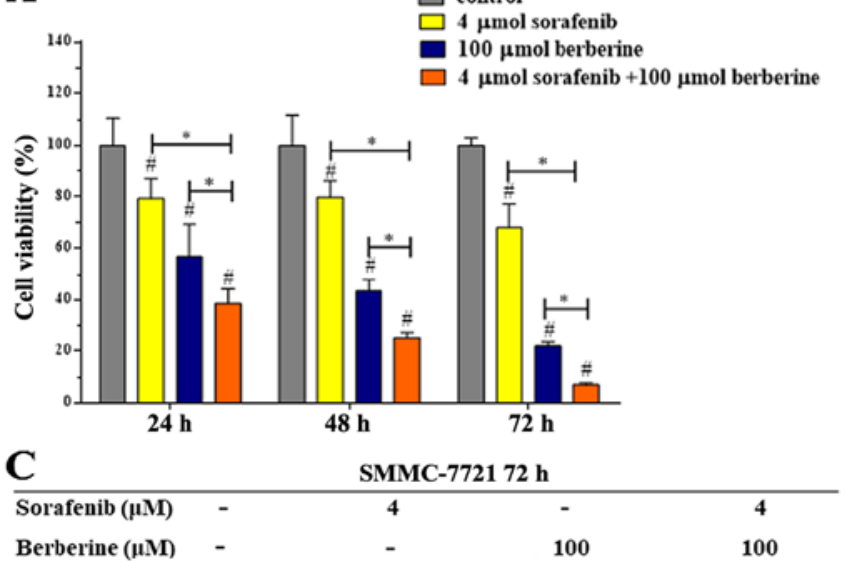

B

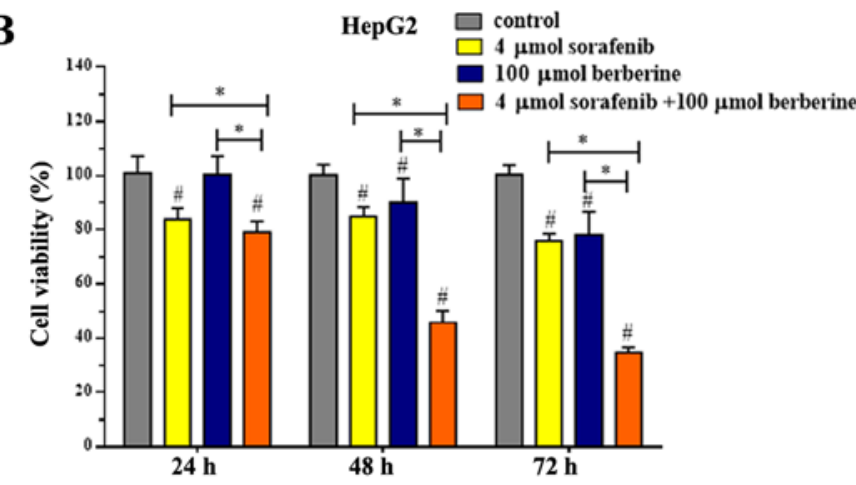

D

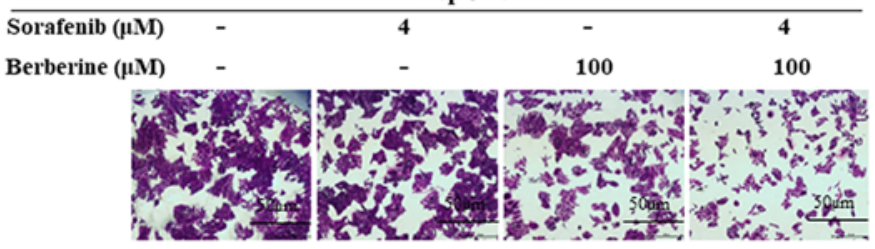

Figure 3. Berberine enhanced the chemosensitivity of hepatocellular carcinoma cells to sorafenib in a time-dependent manner. (A) SMMC-7721 and (B) HepG2 cells were treated with $4 \mu \mathrm{M}$ sorafenib and $100 \mu \mathrm{M}$ berberine alone or in combination $(4 \mu \mathrm{M}$ sorafenib $+100 \mu \mathrm{M}$ berberine) for 24,48 and $72 \mathrm{~h}$. Cell viability was measured by an MTS assay. The growth inhibitory effect of $4 \mu \mathrm{M}$ sorafenib and $100 \mu \mathrm{M}$ berberine alone or in combination $(4 \mu \mathrm{M}$ sorafenib $+100 \mu \mathrm{M}$ berberine $)$ on (C) SMMC-7721 and (D) HepG2 cells was measured by crystal violet staining (magnification, $\mathrm{x} 400$; scale bar, $50 \mu \mathrm{m}$ ). ${ }^{\prime} \mathrm{P}<0.05$ vs. control group; ${ }^{*} \mathrm{P}<0.05$. 
A

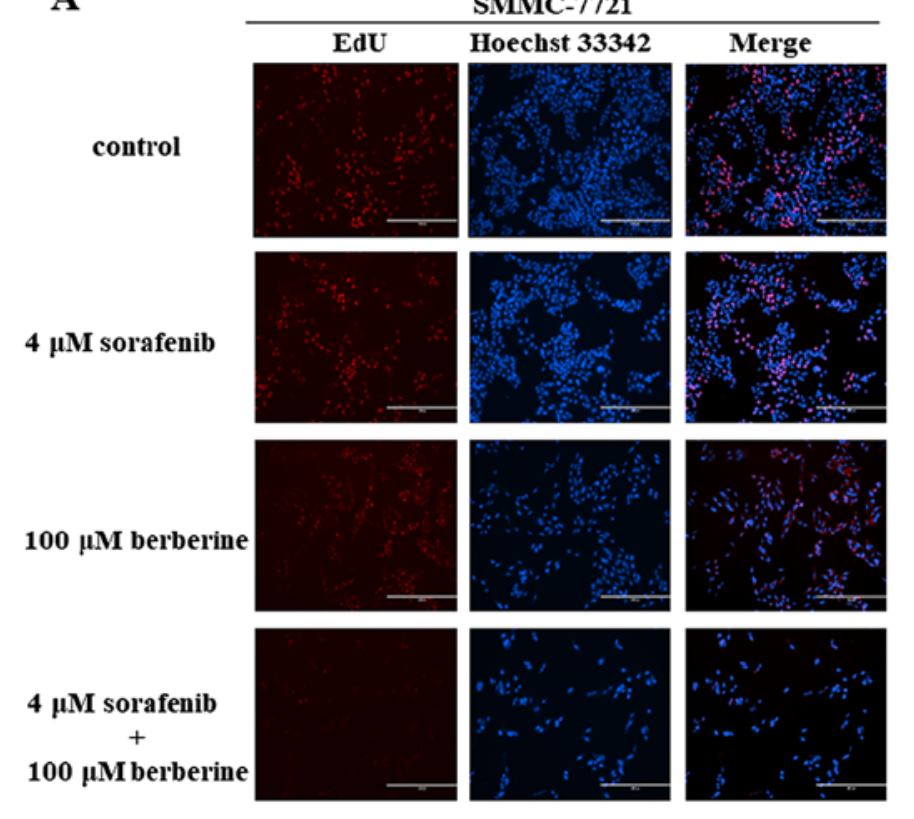

B

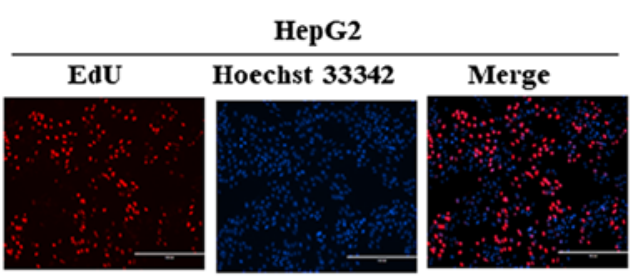

$4 \mu \mathrm{M}$ sorafenib
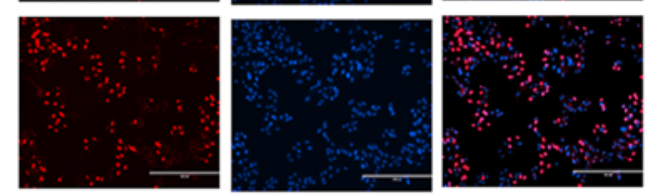

$100 \mu \mathrm{M}$ berberine
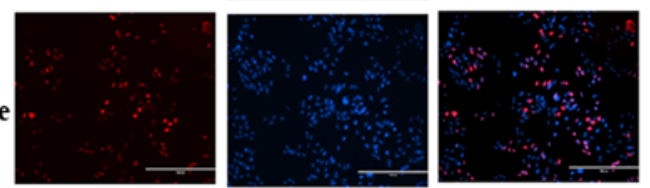

$4 \mu \mathrm{M}$ sorafenib

$+$

$100 \mu \mathrm{M}$ berberine
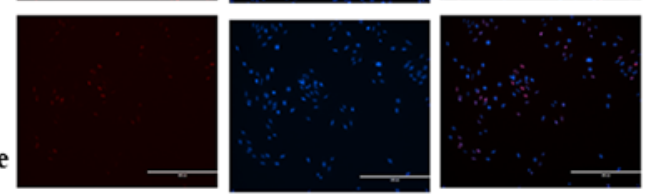

Figure 4. Berberine and sorafenib reduced the proliferative capacity of hepatocellular carcinoma cells. Edu assay was used to evaluate the proliferative capacities of (A) SMMC-7721 and (B) HepG2 cells after treatment with $4 \mu \mathrm{M}$ sorafenib and $100 \mu \mathrm{M}$ berberine alone or in combination $(4 \mu \mathrm{M}$ sorafenib $+100 \mu \mathrm{M}$ berberine) for $48 \mathrm{~h}$ (magnification, $\mathrm{x} 100$ ).

A

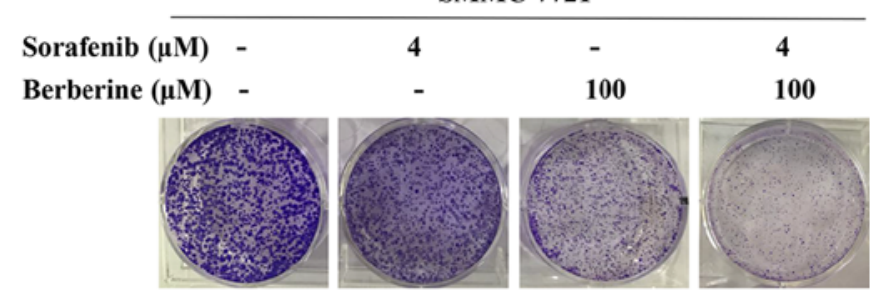

B

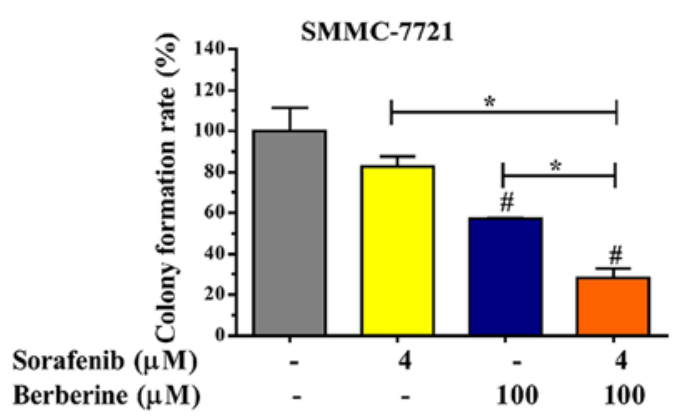

C

\begin{tabular}{cccc}
\multicolumn{4}{c}{ HepG2 } \\
\hline$(\mu \mathrm{M})-$ & 4 & - & 4 \\
$(\mu \mathrm{M})-$ & - & 100 & 100
\end{tabular}

D

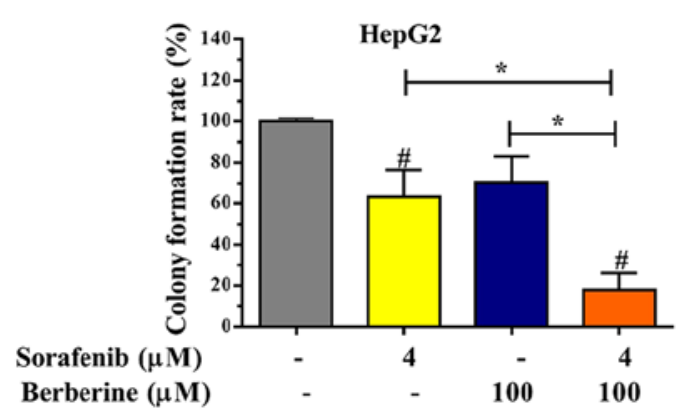

Figure 5. Berberine and sorafenib decreased the proliferative ability of hepatocellular carcinoma cells. A colony formation assay was performed to assess the proliferative abilities of (A) SMMC-7721 and (B) HepG2 cells subsequent to treatment with $4 \mu \mathrm{M}$ sorafenib and $100 \mu \mathrm{M}$ berberine alone or in combination $(4 \mu \mathrm{M}$ sorafenib $+100 \mu \mathrm{M}$ berberine) for $72 \mathrm{~h}$. Quantitative analysis of live cells (purple) in each group was performed for (C) SMMC-7721 and (D) HepG2 cells. The experiments were conducted in triplicate, and data are presented as the mean \pm standard deviation. ${ }^{*} \mathrm{P}<0.05$ vs. the control group; ${ }^{*} \mathrm{P}<0.05$.

Berberine enhances sorafenib-induced apoptosis in HCC cells. To investigate cellular apoptosis induced by combination treatment, SMMC-7721 and HepG2 cells were treated with $100 \mu \mathrm{M}$ berberine and $4 \mu \mathrm{M}$ sorafenib alone or in combination for $72 \mathrm{~h}$. Subsequently, the expression levels of apoptosis-associated proteins were detected by western blot analysis. As shown in Fig. 6A and B, the expression levels of the apoptosis-associated proteins cleaved PARP and cleaved caspase- 3 increased, and the expression of the anti-apoptotic protein $\mathrm{Bcl}-2$ decreased in the combined treatment group when compared with the other groups. In addition, the expression level of VEGF, which is involved in the development of tumor vasculature in the liver, was evidently reduced in the combined treatment group compared with the other groups. These results suggested that berberine increased the sensitivity of HCC cells to sorafenib by inducing cellular apoptosis and inhibiting tumor angiogenesis. 
A

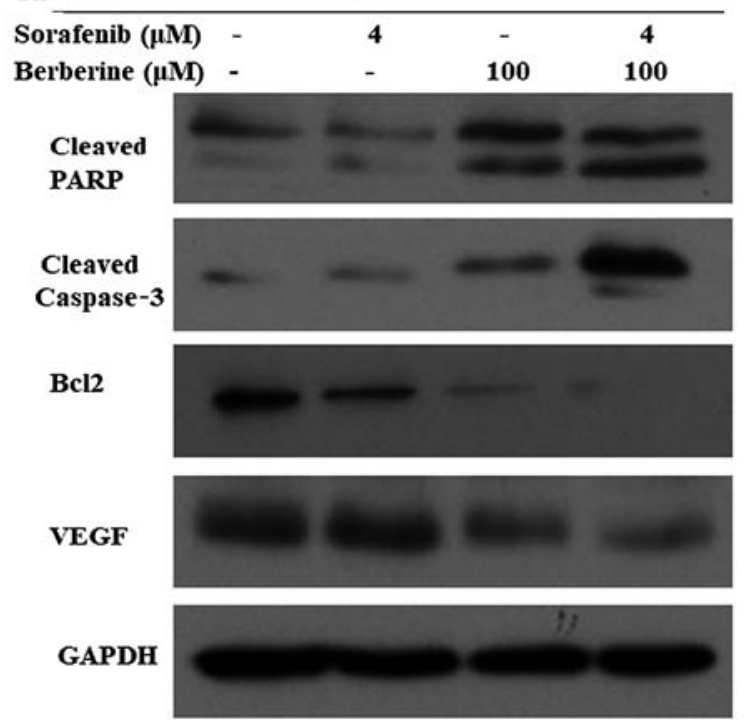

B

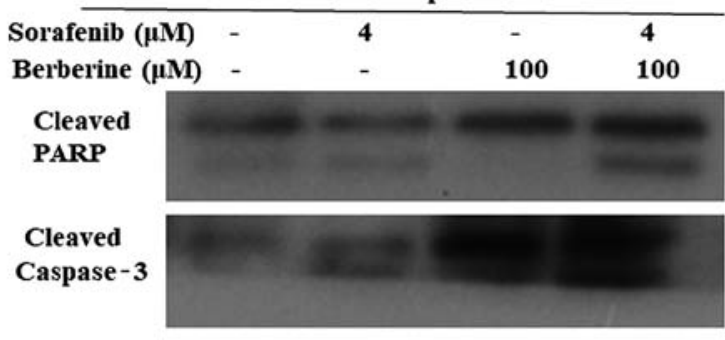

Bcl2

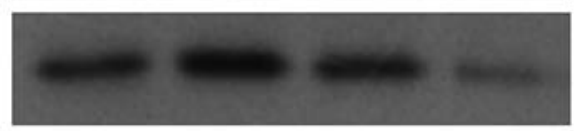

VEGF

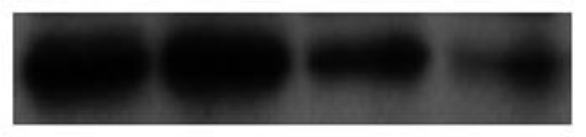

GAPDH

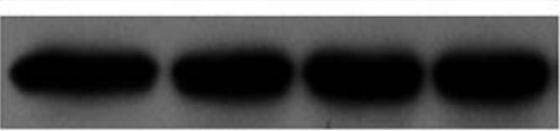

Figure 6. Apoptosis induced by berberine and sorafenib in hepatocellular carcinoma cells. (A) SMMC-7721 and (B) HepG2 cells were treated with $4 \mu \mathrm{M}$ sorafenib and $100 \mu \mathrm{M}$ berberine alone or in combination $(4 \mu \mathrm{M}$ sorafenib $+100 \mu \mathrm{M}$ berberine) for $72 \mathrm{~h}$, and the expression levels of apoptosis-associated proteins were measured by western blot analysis. GAPDH was used as a loading control.

\section{Discussion}

In the present study, the role of berberine in sensitizing HCC cells to sorafenib-induced apoptosis was investigated in vitro. The results indicated that the combination of berberine and sorafenib exhibited synergistic inhibition of the SMMC-7721 and HepG2 cell growth. In addition, berberine enhanced the sorafenib-induced apoptosis in HCC cells. Thus, these findings suggest the therapeutic value of the combination of berberine and sorafenib for patients with HCC.

Sorafenib is an orally available multikinase inhibitor that has been clinically approved for the treatment of patients with advanced HCC. Nevertheless, the survival benefit correlated with sorafenib treatment is limited to approximately three months (23). Almost all patients become refractory within a few months, and adverse effects are common, which is associated with the poor prognosis. Therefore, research has focused on the combination of sorafenib and other chemotherapeutic agents or inhibitors. It has been reported that sorafenib in combination with cisplatin or fluorouracil (5-FU) was beneficial for patients with advanced HCC (24). In the present study, it was found that the combination of $4 \mu \mathrm{M}$ sorafenib and $100 \mu \mathrm{M}$ berberine had a significant inhibitory effect on HCC cell growth, and that the cell viability was reduced by approximately $50-70 \%$. This result indicates that the combination of sorafenib and berberine can increase the sensitivity of HCC cells to sorafenib. In addition, it should be pointed out that we did not find that the typical dose of sorafenib was currently used in cell experiments. To the best of our knowledge, the $\mathrm{IC}_{50}$ concentration of sorafenib varies from different cell lines. It has been reported that the $\mathrm{IC}_{50}$ of sorafenib in HepG2 is $4.3 \mu \mathrm{M}$, in Hep3B is $3.1 \mu \mathrm{M}$, in $\mathrm{HuH7}$ is $7.3 \mu \mathrm{M}$, in HuH6 is $2.8 \mu \mathrm{M}$, and in PLC/PRF5 is $5.5 \mu \mathrm{M}(25)$. Another report showed that the $\mathrm{IC}_{50}$ of sorafenib is $20.85 \pm 2.81 \mu \mathrm{M}, 10.38 \pm 1.52 \mu \mathrm{M}, 10.70 \pm 2.35 \mu \mathrm{M}$ and 9.11 $\pm 2.44 \mu \mathrm{M}$ in SMMC-7721, MHCC97-L, MHCC97-H and
HCCLM6 cells, respectively (26). Therefore, more research is needed to further confirm this study.

Recently, a growing number of studies have reported the anticancer activity of traditional agents extracted from herbal plants (27-29). Berberine is a phytochemical compound isolated from numerous types of medicinal plants and exhibits antitumor properties against various malignancies $(14,30)$. Berberine inhibited the growth of a human colon carcinoma xenograft in nude mice via exhibiting an inhibitory effect on the proliferation of colon cancer cells by binding retinoid $\mathrm{X}$ receptor- $\alpha$ to suppress $\beta$-catenin signaling (17). In breast cancer, berberine inhibited the growth and migration of breast cancer cells via binding to vasodilator-stimulated phosphoprotein (31). In addition, berberine modulated the sensitivity of cisplatin through the miR-93/PTEN/AKT signaling pathway in ovarian cancer cells (32) and attenuated the antitumor activity of 5-FU, camptothecin and paclitaxel (33). Berberine was also found to sensitize cancer cells to PARP and epidermal growth factor receptor inhibitors $(18,34)$. In the present study, berberine and sorafenib were found to exert anti-proliferative effects on HCC cells in a dose- and time-dependent manner. Compared with groups treated with berberine or sorafenib alone, the combined treatment group inhibited cell proliferation and induced apoptosis, which demonstrated that berberine and sorafenib exert a synergistic inhibitory effect on the growth of HCC cells. However, it was observed that $5 \mu \mathrm{M}$ berberine increased cell proliferation instead of suppressing the growth of HCC cells (Fig. 1B). Similar results were detected with combined treatment of $5 \mu \mathrm{M}$ berberine and different concentrations of sorafenib, when compared with the group treated with sorafenib alone (Fig. 2A and B). The above results may be caused by the hormetic effect of berberine. A previous study revealed that low doses $(1.25-5 \mu \mathrm{M})$ of berberine promoted cell proliferation to $112-170 \%$ of the untreated control value in cancer cells, but inhibited cell proliferation at high doses (10-80 $\mu \mathrm{M})$ (33). Furthermore, the degree of growth 
stimulation and the dosage range of berberine notably varied among different types of cancer cells (33). These may be the reasons for the increase in proliferation of HCC cells by $5 \mu \mathrm{M}$ berberine that was observed in the present study.

Chemotherapy-induced apoptosis is a common phenomenon regulated by various apoptosis-associated proteins (35). It has been reported that berberine can induce cellular apoptosis in various types of cancer cells. For instance, Yu et al (36) reported that berberine induced early and late apoptosis of HepG2 cells, leading to caspase-3 cleavage and Bcl-2 degradation. Furthermore, it has been demonstrated that berberine can increase the expression levels of cleaved caspase- 3 and cleaved PARP, and decrease Bcl-2 protein levels in lung cancer cells (37). Consistent with the findings of previous studies, the results of the present study revealed that $100 \mu \mathrm{M}$ berberine induced apoptosis in SMMC-7721 and HepG2 cells. In addition, combined treatment with $100 \mu \mathrm{M}$ berberine and $4 \mu \mathrm{M}$ sorafenib had a more pronounced effect on apoptosis of HCC cells. It was also observed that the protein expression levels of cleaved PARP and cleaved caspase-3 increased, while that of anti-apoptotic protein Bcl-2 decreased in the combined treatment group compared with the groups treated with berberine or sorafenib alone. VEGF has been identified as one of the major initiators in the development and progression of the vascular system (38). Previous research indicated that berberine was able to inhibit the protein expression of VEGF (37). Consistent with this finding, the current study results demonstrated that berberine suppressed the expression of VEGF, which was significantly downregulated in the combined treatment group. VEGF is involved in the development of tumor vasculature in the liver and the infiltration of cancer cells into the tumor capsule in HCC (39). These results suggest that combined treatment with berberine and sorafenib exerts synergistic effects on apoptosis and tumor angiogenesis inhibition.

In conclusion, the present study demonstrated for the first time that berberine synergistically sensitized HCC cells to sorafenib. Combined treatment with berberine and sorafenib inhibited the proliferation of HCC cells and markedly induced cellular apoptosis. These results provide a theoretical basis for the use of berberine and sorafenib in combination as a new chemotherapy regimen for HCC. Further investigations are required to elucidate the molecular and biochemical mechanisms underlying the anticancer effects of combined treatment with berberine and sorafenib, and to provide evidence on the efficacy of the combined treatment in HCC patients.

\section{Acknowledgements}

Not applicable.

\section{Funding}

The present study was supported by grants from the National Natural Science Foundation of China (nos. 81372634 and 81600350), the Guangdong Natural Science Funds for Distinguished Young Scholar (no. S2013050014121), a research project from the Guangdong Province Office of Education (no. 2015KTSCX117) and the Science and Technology Program of Guangzhou (no. 201707010470).

\section{Availability of data and materials}

The datasets used during the present study are available from the corresponding author upon reasonable request.

\section{Authors' contributions}

$\mathrm{YH}$ and $\mathrm{KW}$ generated, analysed and interpretated the data and prepared the manuscript. YH, CG, GY, DZ and WM performed the experiments. YZ, SL and YN analysed the data and prepared the manuscript. $\mathrm{KW}$ and $\mathrm{YH}$ wrote the manuscript. HY generated the idea, designed the study, analysed and interpretated the data, reviewed and edited the manuscript. All authors read and approved the manuscript and agreed to be responsible for all aspects of the study, ensuring that the accuracy or integrity of any part of the work is properly investigated and resolved.

\section{Ethics approval and consent to participate}

This study does not contain any experiments with human subjects or animals.

\section{Patient consent for publication}

Not applicable.

\section{Competing interests}

The authors declare that they have no competing interests.

\section{References}

1. Torre LA, Siegel RL, Ward EM and Jemal A: Global cancer incidence and mortality rates and trends-an update. Cancer Epidemiol Biomarkers Prev 25: 16-27, 2016.

2. Sia D, Villanueva A, Friedman SL and Llovet JM: Liver cancer cell of origin, molecular class, and effects on patient prognosis. Gastroenterology 152: 745-761, 2017.

3. Dutta R and Mahato RI: Recent advances in hepatocellular carcinoma therapy. Pharmacol Ther 173: 106-117, 2017.

4. Keating GM: Sorafenib: A review in hepatocellular carcinoma. Target Oncol 12: 243-253, 2017.

5. Finn RS, Zhu AX, Farah W, Almasri J, Zaiem F, Prokop LJ, Murad MH and Mohammed K: Therapies for advanced stage hepatocellular carcinoma with macrovascular invasion or metastatic disease: A systematic review and meta-analysis. Hepatology 67: 422-435, 2017.

6. Adnane L, Trail PA, Taylor I and Wilhelm SM: Sorafenib (BAY 43-9006, Nexavar), a dual-action inhibitor that targets RAF/MEK/ERK pathway in tumor cells and tyrosine kinases VEGFR/PDGFR in tumor vasculature. Methods Enzymol 407: 597-612, 2006.

7. Wilhelm S, Carter C, Lynch M, Lowinger T, Dumas J, Smith RA, Schwartz B, Simantov R and Kelley S: Discovery and development of sorafenib: A multikinase inhibitor for treating cancer. Nat Rev Drug Discov 5: 835-844, 2006.

8. Zhou C, Liu J, Li Y, Liu L, Zhang X, Ma CY, Hua SC, Yang M and Yuan Q: microRNA-1274a, a modulator of sorafenib induced a disintegrin and metalloproteinase 9 (ADAM9) down-regulation in hepatocellular carcinoma. Febs Lett 585: 1828-1834, 2011.

9. Potenza N, Mosca N, Zappavigna S, Castiello F, Panella M, Ferri C, Vanacore D, Giordano A, Stiuso P, Caraglia M and Russo A: MicroRNA-125a-5p is a downstream effector of sorafenib in its antiproliferative activity toward human hepatocellular carcinoma cells. J Cell Physiol 232: 1907-1913, 2017.

10. Chen J, Jin R, Zhao J, Liu J, Ying H, Yan H, Zhou S, Liang Y, Huang D, Liang X, et al: Potential molecular, cellular and microenvironmental mechanism of sorafenib resistance in hepatocellular carcinoma. Cancer Lett 367: 1-11, 2015. 
11. Alsaied OA, Sangwan V, Banerjee S, Krosch TC, Chugh R, Saluja A, Vickers SM and Jensen EH: Sorafenib and triptolide as combination therapy for hepatocellular carcinoma. Surgery 156 270-279, 2014

12. Li S, Dai W, Mo W, Li J, Feng J, Wu L, Liu T, Yu Q, Xu S, Wang $\mathrm{W}$, et al: By inhibiting PFKFB3, aspirin overcomes sorafenib resistance in hepatocellular carcinoma. Int J Cancer 141: 2571-2584, 2017.

13. Ayati SH, Fazeli B, Momtazi-Borojeni AA, Cicero A, Pirro M and Sahebkar A: Regulatory effects of berberine on microRNome in Cancer and other conditions. Crit Rev Oncol Hematol 116 : 147-158, 2017.

14. Tillhon M, Guaman OL, Lombardi P and Scovassi AI: Berberine: New perspectives for old remedies. Biochem Pharmacol 84 1260-1267, 2012.

15. Li-Weber M: Targeting apoptosis pathways in cancer by Chinese medicine. Cancer Lett 332: 304-312, 2013.

16. Tan W, Li Y, Chen M and Wang Y: Berberine hydrochloride: Anticancer activity and nanoparticulate delivery system. Int J Nanomedicine 6: 1773-1777, 2011.

17. Ruan H, Zhan YY, Hou J, Xu B, Chen B, Tian Y, Wu D, Zhao Y, Zhang Y, Chen X, et al: Berberine binds RXR $\alpha$ to suppress $\beta$-catenin signaling in colon cancer cells. Oncogene 36: 6906-6918, 2017.

18. Wang J, Yang S, Cai X, Dong J, Chen Z, Wang R, Zhang S, Cao $\mathrm{H}, \mathrm{Lu} \mathrm{D}$, Jin $\mathrm{T}$, et al: Berberine inhibits EGFR signaling and enhances the antitumor effects of EGFR inhibitors in gastric cancer. Oncotarget 7: 76076-76086, 2016.

19. Li M, Zhang M, Zhang ZL, Liu N, Han XY, Liu QC, Deng WJ and Liao CX: Induction of apoptosis by berberine in hepatocellular carcinoma HepG2 cells via downregulation of NF- $\kappa \mathrm{B}$. Oncol Res 25: 233-239, 2017.

20. Ayati SH, Fazeli B, Momtazi-Borojeni AA, Cicero A, Pirro M and Sahebkar A: Regulatory effects of berberine on microRNome in Cancer and other conditions. Crit Rev Oncol Hematol 116 147-158, 2017.

21. Wang XN, Han X, Xu LN, Yin LH, Xu YW, Qi Y and Peng JY: Enhancement of apoptosis of human hepatocellular carcinoma SMMC-7721 cells through synergy of berberine and evodiamine. Phytomedicine 15: 1062-1668, 2008.

22. Youn MJ, So HS, Cho HJ, Kim HJ, Kim Y, Lee JH, Sohn JS, Kim YK, Chung SY and Park R: Berberine, a natural product, combined with cisplatin enhanced apoptosis through a mitochondria/caspase-mediated pathway in HeLa cells. Biol Pharm Bull 31: 789-795, 2008.

23. Llovet JM, Ricci S, Mazzaferro V, Hilgard P, Gane E, Blanc JF, de Oliveira AC, Santoro A, Raoul JL, Forner A, et al: Sorafenib in advanced hepatocellular carcinoma. N Engl J Med 359: 378-390, 2008

24. Ueshima K, Kudo M, Tanaka M,Kumada T, Chung H,Hagiwara S, Inoue T, Yada $\mathrm{N}$ and Kitai S: Phase I/II study of sorafenib in combination with hepatic arterial infusion chemotherapy using low-dose cisplatin and 5-fluorouracil. Liver Cancer 4: 263-273, 2015 .
25. Blivet-Van EM, Chettouh H, Fartoux L, Aoudjehane L, Barbu V, Rey C, Priam S, Housset C, Rosmorduc O and Desbois-Mouthon C: Epidermal growth factor receptor and HER-3 restrict cell response to sorafenib in hepatocellular carcinoma cells. J Hepatol 57: 108-115, 2012.

26. Zhang Z, Zhou X, Shen H, Wang D and Wang Y: Phosphorylated ERK is a potential predictor of sensitivity to sorafenib when treating hepatocellular carcinoma: Evidence from an in vitro study. BMC Med 7: 41, 2009.

27. Yang $\mathrm{X}$ and $\mathrm{Wu} \mathrm{XZ}$ : Main antitumor angiogenesis agents isolated from chinese herbal medicines. Mini Rev Med Chem 15: 1011-1023, 2015

28. Lin M, Bi H, Yan Y, Huang W, Zhang G, Zhang G, Tang S, Liu Y, Zhang L, Ma J, et al: Parthenolide suppresses non-small cell lung cancer GLC-82 cells growth via B-Raf/MAPK/Erk pathway. Oncotarget 8: 23436-23447, 2017.

29. He QL, Minn I, Wang Q, Xu P, Head SA, Datan E, Yu B, Pomper MG and Liu JO: Targeted delivery and sustained antitumor activity of triptolide through glucose conjugation. Angew Chem Int Ed Engl 55: 12035-12039, 2016.

30. Sun Y, Xun K, Wang Y and Chen X: A systematic review of the anticancer properties of berberine, a natural product from Chinese herbs. Anticancer Drugs 20: 757-769, 2009.

31. Su K, Hu P, Wang X, Kuang C, Xiang Q, Yang F, Xiang J, Zhu S, Wei $L$ and Zhang J: Tumor suppressor berberine binds VASP to inhibit cell migration in basal-like breast cancer. Oncotarget 7: 45849-45862, 2016.

32. Chen Q, Qin R, Fang Y and Li H: Berberine sensitizes human ovarian cancer cells to cisplatin through miR-93/PTEN/ Akt signaling pathway. Cell Physiol Biochem 36: 956-965, 2015.

33. Bao J, Huang B, Zou L, Chen S, Zhang C, Zhang Y, Chen M, Wan JB, Su H, Wang Y and He C: Hormetic effect of berberine attenuates the anticancer activity of chemotherapeutic agents. PLoS One 10: e139298, 2015

34. Hou D, Xu G, Zhang C, Li B, Qin J, Hao X, Liu Q, Zhang X, Liu J, Wei J, et al: Berberine induces oxidative DNA damage and impairs homologous recombination repair in ovarian cancer cells to confer increased sensitivity to PARP inhibition. Cell Death Dis 8: e3070, 2017.

35. Das T, Sa G, Saha B and Das K: Multifocal signal modulation therapy of cancer: Ancient weapon targets. Mol Cell Biochem 336: $85-95,2010$

36. Yu R, Zhang ZQ, Wang B, Jiang HX, Cheng L and Shen LM: Berberine-induced apoptotic and autophagic death of HepG2 cells requires AMPK activation. Cancer Cell Int 14: 49, 2014.

37. Fu L, Chen W, Guo W, Wang J, Tian Y, Shi D, Zhang X, Qiu H, Xiao X, Kang T, et al: Berberine Targets AP-2/hTERT, $\mathrm{NF}-\kappa \mathrm{B} / \mathrm{COX}-2, \mathrm{HIF}-1 \alpha / \mathrm{VEGF}$ and cytochrome-c/caspase signaling to suppress human cancer cell growth. PLoS One 8: e69240, 2013.

38. Ferrara N, Gerber HP and LeCouter J: The biology of VEGF and its receptors. Nat Med 9: 669-676, 2003.

39. Wang H, Zhang C, Ning Z, Xu L, Zhu X and Meng Z: Bufalin enhances anti-angiogenic effect of sorafenib via AKT/VEGF signaling. Int J Oncol 48: 1229-12241, 2016. 